\title{
Mitral valve replacement with ball valve prostheses
}

\author{
Albert Starr \\ From the Division of Cardiopulmonary Surgery, University of Oregon \\ Medical School, Portland, Oregon 97201, U.S.A.
}

Our experience with ball valve replacement of the mitral valve during the past decade is presented in terms that allow comparison with other techniques. The use of such prostheses is characterized by ease of implantation, with an overall operative mortality of II per cent for isolated mitral replacement and 13 per cent for multiple valve replacement. The operative mortality for isolated mitral valve replacement during 1969 and thus far in 1970 has been nil. The late mortality was 13 per cent for isolated mitral replacement and 20 per cent for multiple valve replacement. Forty-three per cent of the total late deaths were clearly unrelated to the prosthetic device itself.

The overall incidence of late infection and leak is less than I per cent and the immediate haemodynamic benefit is not altered by loss of structural integrity of the prosthesis.

The most serious problem after mitral valve replacement with the ball valve prosthesis is that of thromboembolic complications. While thrombotic stenosis of the prosthesis is a rarity, embolic episodes, usually cerebral in type, have been noted in 63 per cent of the patients surviving mitral valve replacement with the earliest model ball valve from August 1960 to February 1966. Improvements in valve design have resulted in a remarkable decrease in this incidence as examined by actuarial techniques and taking into account the duration of follow-up. The extension of the cloth sewing margins to the orifice of the valve while maintaining a metallic orifice and metallic cage (Model 6120) resulted in a drop of the thromboembolic rate to 17 per cent from April 1965 to April 1969.

The development of the totally cloth-covered prosthesis has further improved these results, with only one thromboembolic complication after isolated mitral valve replacement with the Model 6310 valve in a series of 66 consecutive patients. In clinical practice this has resulted in the avoidance of the use of anticoagulant therapy in patients in whom for a variety of reasons this carries an increased hazard. With further follow-up it may be possible to discontinue the routine use of anticoagulants.

The past decade has seen considerable progress in the surgical management of mitral valve disease. The selection of patients for operation, the application of a replacement or reparative procedure, and the physiological basis for sound postoperative care are well established. However, the method of choice for replacement of the mitral valve, whether by prostheses of synthetic material, prostheses of diverse biological material, or autogenous tissue, is still under consideration.

Our own experience has been overwhelmingly with the ball valve prostheses (Starr and Edwards, 196I). The purpose of this report is to review this experience in terms of early and late morbidity and mortality in a manner that allows easy comparison with other techniques. The control of thromboembolic complications by a logical sequence of changes in design of the ball valve prostheses is clearly shown. The results obtained with the current generation of such valves provide a standard to be met by alternative techniques.

\section{Clinical Material}

Our experience with open heart surgery of the mitral valve is shown in Fig. I. During the decade from August I960 to June 1970, of 754 such patients 29 per cent had a reparative procedure, 4I per cent had isolated mitral valve replacement, and 30 per cent had multiple valve replacement. In the replacement group the ages ranged from 13 to 74 with a mean of 49 . All the patients were New York Heart Classification III or IV. All patients requiring multiple valve replacement and most of the isolated valve patients had chronic rheumatic valvulitis. Replacement was performed in rare instances for congenital abnormalities such as atrioventricular canal or congenital mitral stenosis. While most patients with ruptured chordae tendineae had a reparative operation, in some 


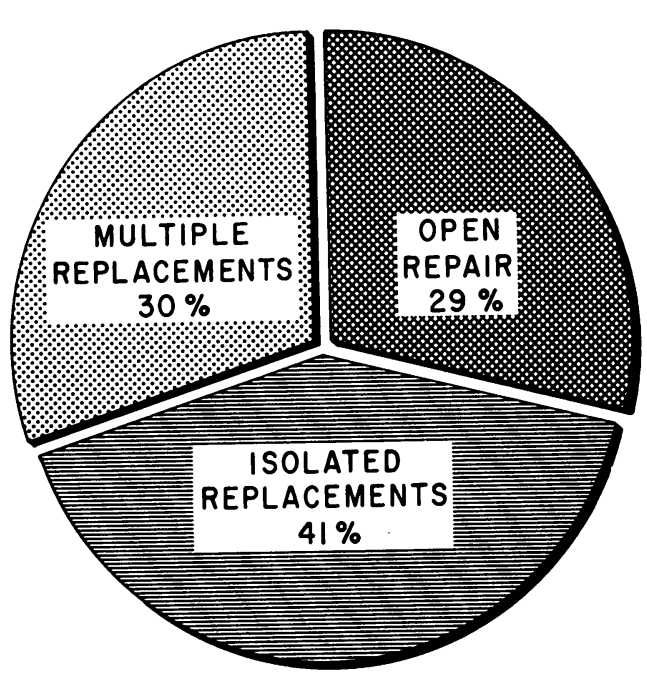

FIG. I Open heart surgery of the mitral valve in 754 patients from August 1960 to June 1970.

instances in which the ruptures were multiple a replacement was performed.

The importance of correction of associated valve disease was recognized early in our experience (Starr et al., 1964a, b). The first combined mitral and aortic replacement was performed in July 1962 and the first triple valve replacement in February 1963. While preoperative haemodynamic and contrast studies were performed in most patients, the median sternal splitting approach was adopted to allow a thorough reassessment of all the valvular pathology so that total correction could be performed. The management of tricuspid valve disease is as previously reported (Starr, Herr, and Wood, I966a; Starr, 1969). While tricuspid commissurotomy is applicable to some patients, tricuspid valve replacement is performed in most patients with severe organic tricuspid valve disease. The tricuspid valve is also replaced in patients with faradvanced and irreversible functional tricuspid regurgitation. This condition is due to prolonged right ventricular hypertrophy and dilatation and results in a relative subvalvular shortening associated with varying degrees of annular dilatation. In our experience annuloplasty has not been effective in overcoming this complex disproportion between valve and ventricle over the long term.

During the past few years coronary arteriography has been used with increasing frequency in patients over 40 years of age. Patients with associated coronary lesions amenable to saphenous vein bypass procedures have been accepted for combined operations. Patients with advanced and irreparable coronary artery disease are excluded for operation.

\section{Prostheses}

The various models of the mitral ball valve prosthesis used in man from August 1960 to the present time are shown in Fig. 2. The first two patients had implantation of a lucite caged valve with silicone rubber ball and Teflon sewing ring (Fig. 2A). This was a bulky prosthesis with considerable clearance between the ball and cage legs and a relatively small orifice to ball ratio. Both valves were recovered at necropsy without evidence of deterioration or malfunction. In one patient the valve was well healed without thrombus formation and death was due to an arrhythmia related to myocardial fibrosis occurring five years after implantation. In the other, death was due to thromboembolic disease ten years after implantation. Considerable thrombus was found on the exposed lucite surfaces.

Subsequent patients had implantation of a metallic caged ball valve, the first few of stainless steel and the remainder of Stellite 2I. These are divided into four major models: the 6000, 6120,6300 , and 6310 series. A critical evaluation of our clinical results must be made in terms of valve design. The Model 6000 valve (Fig. 2B) has a broad metallic outflow and inflow face, relatively thick struts, a long stroke, a small ball to orifice ratio, and a silicone rubber ball. In March 1965 this was supplanted by the Model 6120 series with changes aimed at improving hydraulic function, reducing cage size, and reducing the incidence of thromboembolic complications. In this prosthesis the Teflon cloth sewing margin was extended to the orifice so that the broad metallic surfaces, both on the inflow and outflow face of the base of the prosthesis, were removed. A flange-shaped sewing ring was intro-

FIG. 2 Starr-Edwards mitral prostheses. $(A)$ Early prototype. (B) Model 6000. (C) Model 6I20. (D) Model 6300.
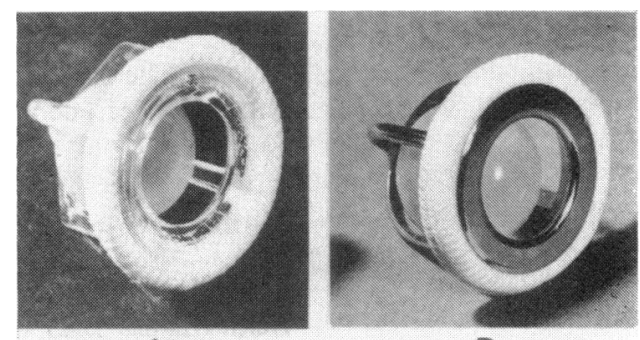

A

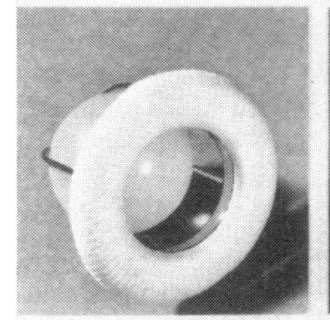

B

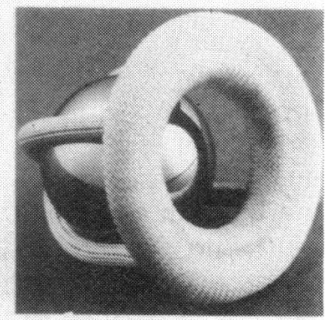

D 
duced which would overlap the mitral annulus on the atrial side and diminish the incidence of perivalvular leak. The struts were thinned, the orifice to ball ratio increased, the stroke decreased, and the clearance between the silicone rubber ball and the struts was decreased to further reduce the bulk of the cage. This prosthesis provided superior hydraulic function to the previous model of the same external dimensions (Fig. $2 \mathrm{C}$ ).

In April 1967, after two years of experience in the animal laboratory, the first totally clothcovered prosthesis was used in man for mitral replacement in the form of the Model 6300 series (Fig. 2D). This prototype valve contained a hollow metallic ball of Stellite with a specific gravity of 0900 in a cage of Stellite 21 covered by Dacron or more commonly Teflon cloth, or both. Fig. 3 shows a Model 6300 in place nine months after implantation in a patient killed in an automobile accident. There is complete covering of the valve with a glistening transparent autogenous tissue.

In order to protect the cloth in the orifice from the shear forces produced by ball closure the orifice to ball ratio was reduced considerably, resulting in some decrease in hydraulic performance as compared with the Model 6120. This was confirmed by postoperative cardiac catheterization and led, in December I968, to the clinical use of the current cloth-covered 6310 series (Fig. 4). This prosthesis has a sewing ring of Teflon and polypropylene, the former for lubricity and the latter for structural integrity. The struts are covered with two layers of cloth: an inner Teflon layer to form a suitable bed for an outer layer of polypropylene. The orifice to ball ratio was increased to produce hydraulic function comparable to the Model 6r20. Protection of the cloth in the orifice is provided by small metallic studs spaced between Teflon or currently polypropylene fibres. Fig. 5 shows a composite orifice valve (Model 6310) removed nine months after implantation because of a large perivalvular leak. Neointima covers the entire valve except for the small metallic studs. There is no thrombus material at the junction of the metallic studs and cloth.

With the introduction of the composite seat, tear of the orifice cloth has not been seen. Partial thickness tear of the strut cloth with the earlier model totally cloth-covered valve (Model 6300) has been observed in one specimen in our series but was of no functional consequence. A strut cloth tear has not been seen with the current strut covering of double layer Teflon or inner layer Teflon and outer layer polypropylene. Much has been learned about the mechanism and correction of strut cloth tear from extracorporeal accelerated fatigue tests. These show that the first step in the process is a spreading apart of the longitudinal fibres on the inner aspect of the strut, followed by wearing down of the transverse fibres due to contact with the ball. Measures taken to avoid separation of longitudinal fibres and to lessen lateral excursion of the ball have greatly diminished the rate at which cloth tear may occur. In addition, polypropylene is superior to Tefion or Dacron in this respect. It is not likely, there-

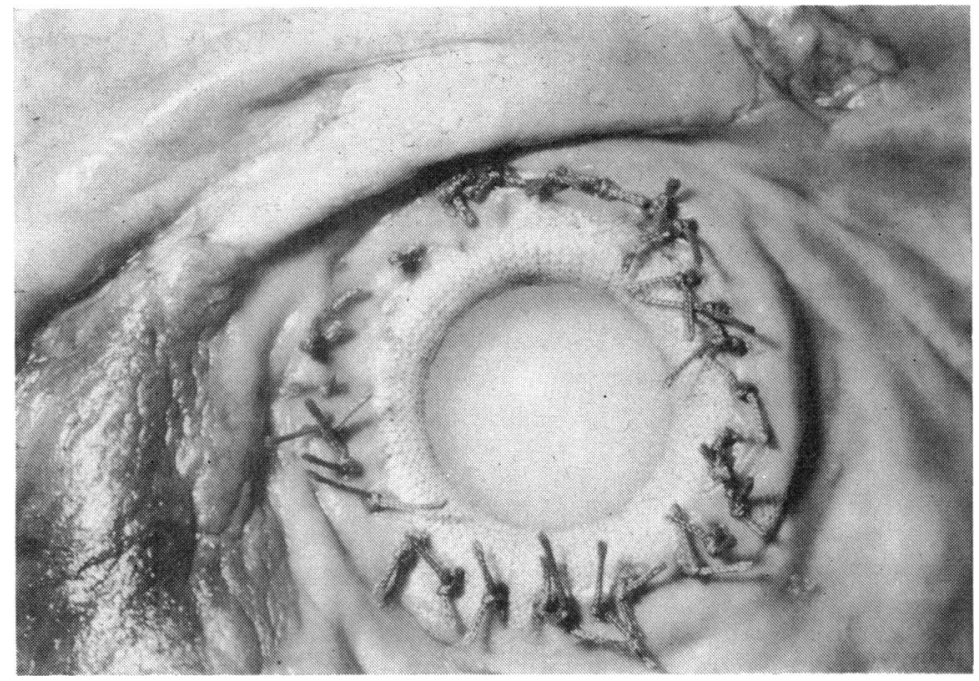

FIG. 3 Model 6300 mitral prosthesis nine months after implantation. Note absence of thrombus material and the glistening neointima covering the cloth surfaces.

fore, that strut cloth tear will be a significant problem after mitral valve replacement with totally cloth-covered valves. Careful and continued observation, however, will be necessary to confirm this, since extracorporeal fatigue studies cannot be used as an accurate projection of in vivo future performance.

FIG. 4 Model 6310 with sewing ring of Teflon and polypropylene.

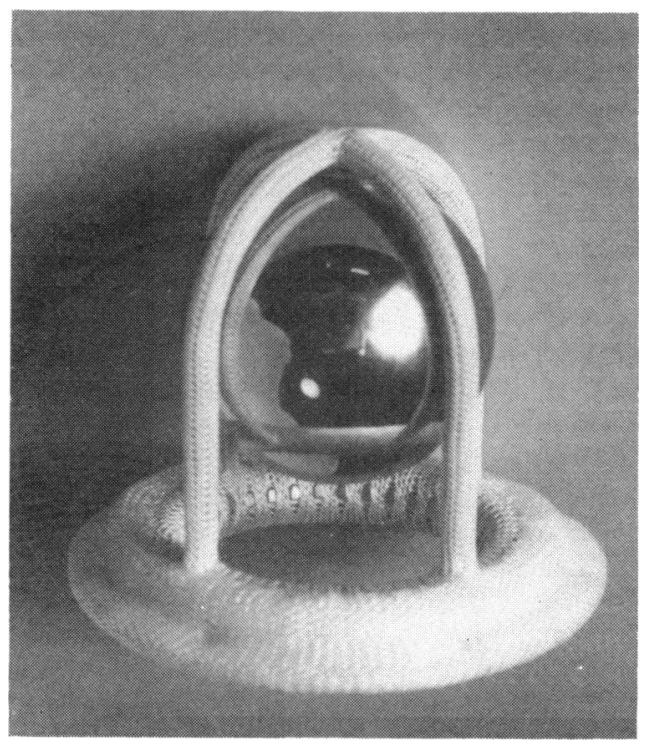




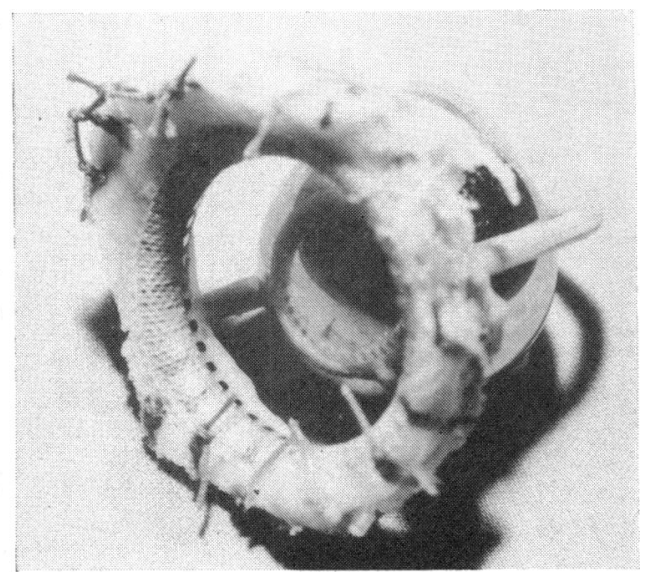

FIG. 5 Model 6310 prosthesis removed nine months after implantation because of perivalvular leak. Note the glistening neointima covering the cloth up to the metallic studs. No thrombus is present on the valve.

\section{Results}

The operative mortality in this series consists of all deaths occurring during the first month after implantation, or occurring later but due to a complication starting in the first month (Table I). There has been a sharp reduction

TABLE I Total mitral valve replacement: Operative mortality in 544 patients, August I960 to fune 1970

\begin{tabular}{lrl}
\hline & $\begin{array}{l}\text { No. of } \\
\text { patients }\end{array}$ & $\begin{array}{l}\text { Operative } \\
\text { mortality (\%) }\end{array}$ \\
\hline Isolated & & \\
1960-1968 & 241 & 13 \\
1969-1970 & 71 & 0 \\
Multiple & & \\
1960-1968 & 182 & 13 \\
1969-1970 & 50 & 12 \\
\hline
\end{tabular}

in operative risk in patients having isolated mitral replacement with no mortality in 1969 and thus far in 1970. All of these patients had implantation of the Model 6310 prosthesis. The immediate risk of multiple valve replacement of 12 to 13 per cent has not changed with increasing experience. The overall operative and late mortality for isolated and multiple valve replacement is shown in Fig. 6. While the operative mortality is comparable in both groups, the late death rate is higher in the multiple valve patients. The risk in tricuspid valve replacement is shown in Table 2 and

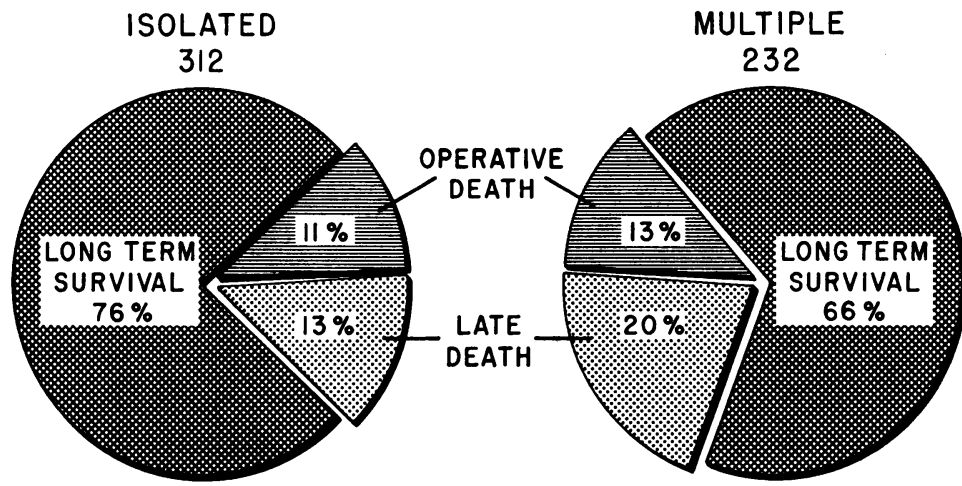

FIG. 6 Overall operative and late mortality for isolated and multiple valve replacement.

TABLE 2 Tricuspid valve replacement. Mortality, February 1963 to March 1970

\begin{tabular}{|c|c|c|c|}
\hline \multirow[t]{2}{*}{ Replacement type } & \multirow{2}{*}{$\begin{array}{l}\text { No. of } \\
\text { patients }\end{array}$} & \multicolumn{2}{|c|}{$\%$ Mortality } \\
\hline & & Operative & Late \\
\hline $\begin{array}{l}\text { Mitral and tricuspid } \\
\text { Triple }\end{array}$ & $\begin{array}{l}44 \\
44\end{array}$ & $\begin{array}{l}14 \\
16\end{array}$ & $\begin{array}{r}2 \\
18\end{array}$ \\
\hline
\end{tabular}

TABLE 3 Cause of late death

\begin{tabular}{lrr} 
& Isolated & Multiple \\
\hline Related to prosthesis & & \\
Bacterial endocarditis & 2 & 2 \\
Mechanical (ball variance, leak) & 0 & 3 \\
Thromboembolism & 10 & 15 \\
Reoperation & 0 & 2 \\
No necropsy or unknown & 4 & 12 \\
Unrelated to prosthesis & & \\
Heart related & & \\
Coronary artery disease & 4 & 5 \\
$\quad$ Chronic congestive failure & 0 & 3 \\
Myocardial fibrosis & 6 & 3 \\
Arrhythmias, sudden death & 3 & 3 \\
Residual valve disease & 1 & 0 \\
Other disease or trauma & 7 & 2 \\
\hline Total & 37 & 50 \\
\hline
\end{tabular}

does not differ from the remainder of the series.

The causes of late death are listed in Table 3. These are divided into those possibly related to the presence of an intracardiac prosthesis or those clearly unrelated to the prosthesis. The incidence of fatal thromboembolic complications is greater in the multiple valve patients and this accounts in part for 
the increased late mortality. The reason for this is the greater possibility of coronary embolus after aortic valve replacement compared with isolated mitral replacement. The special referral of patients from distant centres to Oregon for multiple valve replacement accounts for the larger number of such patients without necropsy information compared with the isolated valve replacement group. Coronary artery disease was one of the more common causes of late death. In addition, there were many instances of myocardial fibrosis leading to death from chronic congestive heart failure or from sudden arrhythmia unrelated to coronary artery disease. The aetiology of myocardial fibrosis in these patients was not apparent on histological examination.

Time-related mortality and morbidity rates

An evaluation of late death and morbidity must be related to the duration of follow-up to provide meaningful data. The incidence of bacterial endocarditis, reoperation, late death, and thromboembolic complications is shown

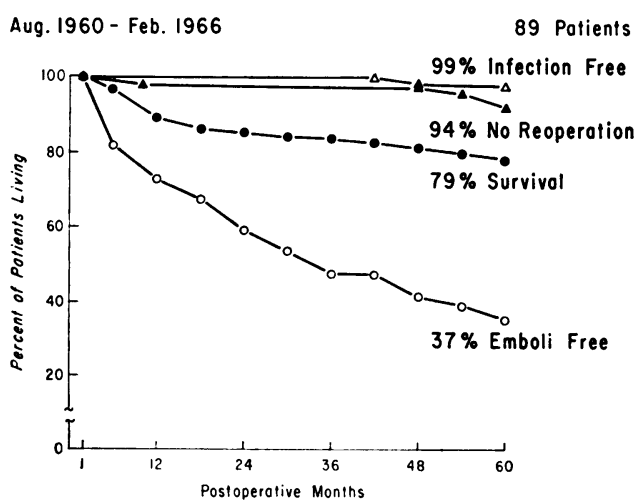

FIG. 7 Isolated mitral valve replacement.

Model 6000.

for the various model ball valves in a series of actuarial curves in Fig. 7 to 14 . The number of patients without these complications as a ,ercentage of the total number surviving at the end of the first postoperative month is plotted against the months of follow-up. The curves are not extended beyond an arbitrary interval, the longest being five years, since the number of patients becomes very small. For each model valve two curves have been drawn, one for isolated mitral replacement and one for mitral replacement associated with replacement of another valve.

These charts show that while bacterial

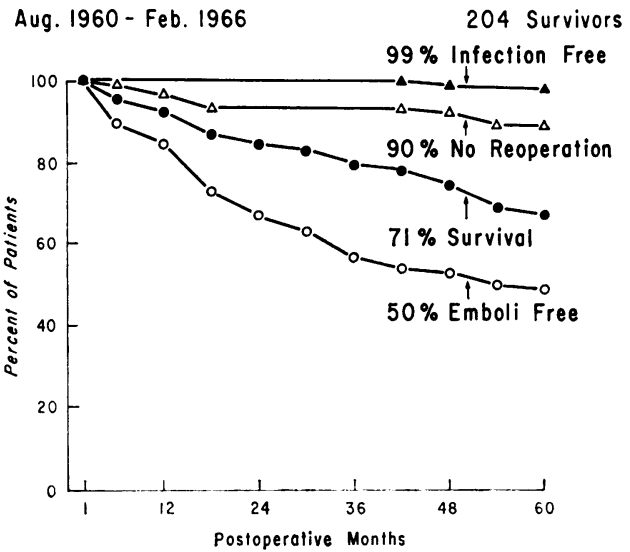

FIG. 8 Total mitral valve replacement. Model 6000.

April 1965 - April 1969

71 Survivors

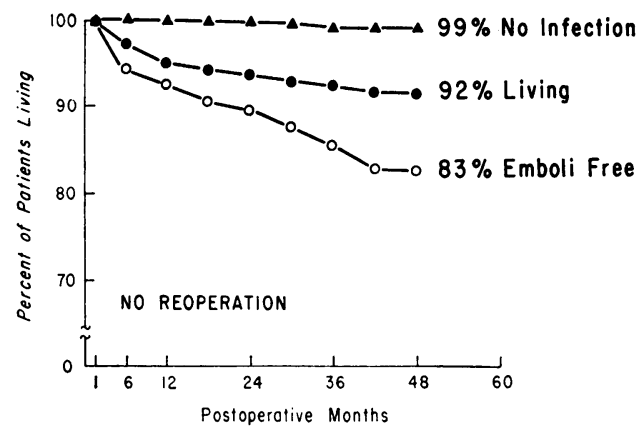

FIG. 9 Isolated mitral valve replacement. Model 6I20.

April 1965 - Jan. 1969

122 Potients

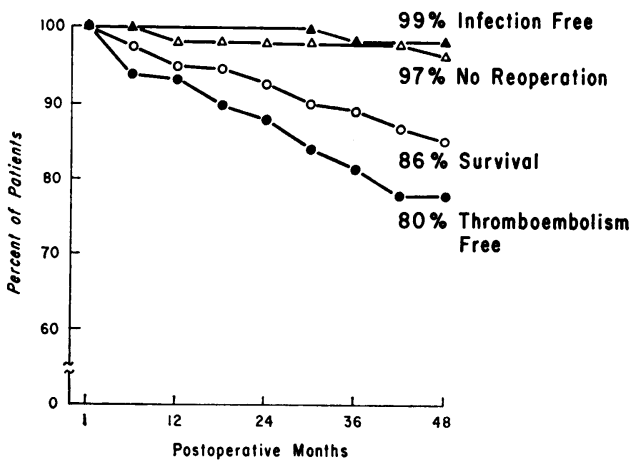

FIG. IO Total mitral valve replacement. Model 6120. 
Sept. 1967 - Dec. 1968

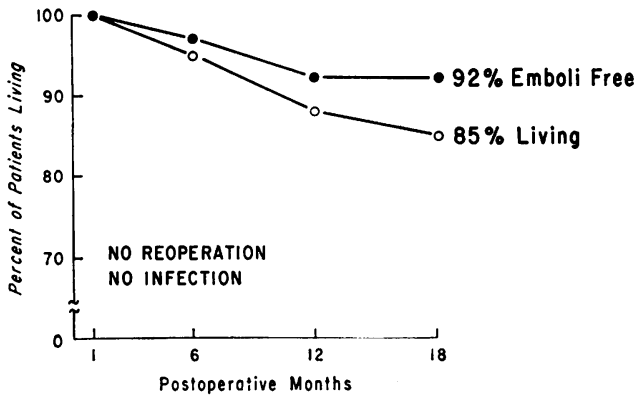

FIG. II Isolated mitral valve replacement. Model 6300.

endocarditis may occur many months or years after operation, the incidence is between $o$ and 2 per cent for various model valves. The need for reoperation is ro per cent at the end of five years in the multiple valve series and 6 per cent in the isolated valve series with the old Model 6000 prosthesis. This reflects the high incidence of perivalvular leak early in our experience with mitral replacement, before the development of the high porosity, compressible flange-shaped sewing ring. The higher incidence of reoperation in the multiple valve group results from the problem of ball variance with the earlier Model 1000 aortic prosthesis. The reoperation rate at 48 months for the Model 6120 mitral prosthesis is much lower with 3 per cent for the multiple valve series and 0 per cent for the isolated valve series. The improvement in the late death rate with the Model 6120 prosthesis compared with the earlier Model 6000 prosthesis is related to the greatly diminished incidence of thromboembolic complications with the former. Thus at 60 months only 37 per cent of the patients with isolated mitral replacement with the Model 6000 valve are free of thromboembolic complications, while at 48 months 83 per cent are emboli free with a comparable series of Model 6r20. The difference in the slope of the curves in Fig. I 5 for the two prostheses is striking. It is also apparent from this figure that the current Model 63ro prosthesis has resulted in further improvements compared with the 6r20 valve with only one embolus occurring at three months in the isolated valve series and two emboli in the multiple valve series, the latest at 14 months.

The overall incidence and severity of late thromboembolic complications in 448 longterm surviving patients is shown in Fig. I6. More than one half of the thromboembolic episodes were transient hemiparesis, or
Sept. 1967 - Dec. 1968

68 Potients

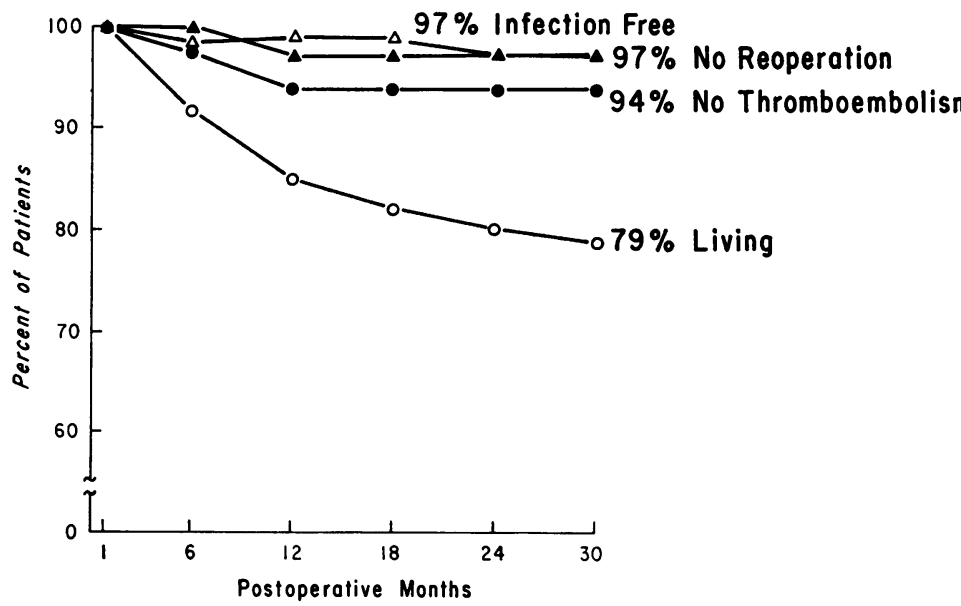

FIG. I2 Total mitral valve replacement. Model 6300.

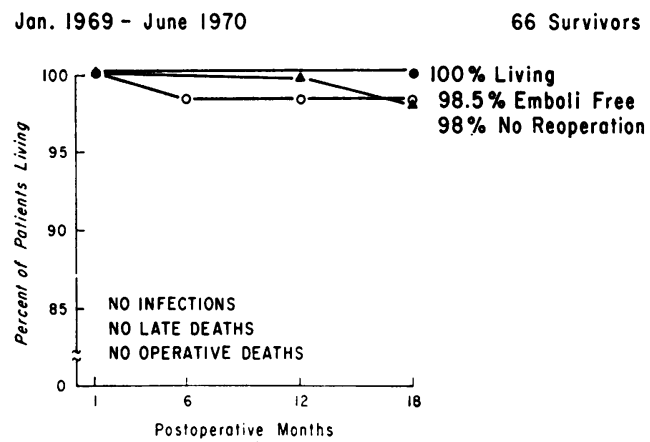

FIG. I3 Isolated mitral valve replacement. Model 6310.

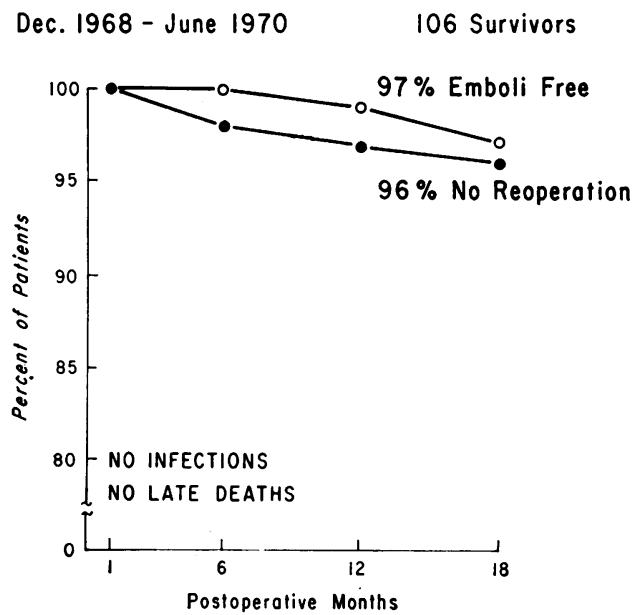

FIG. I4 Total mitral valve replacement. Model 6310. 
Aug. 1960 - June 1970

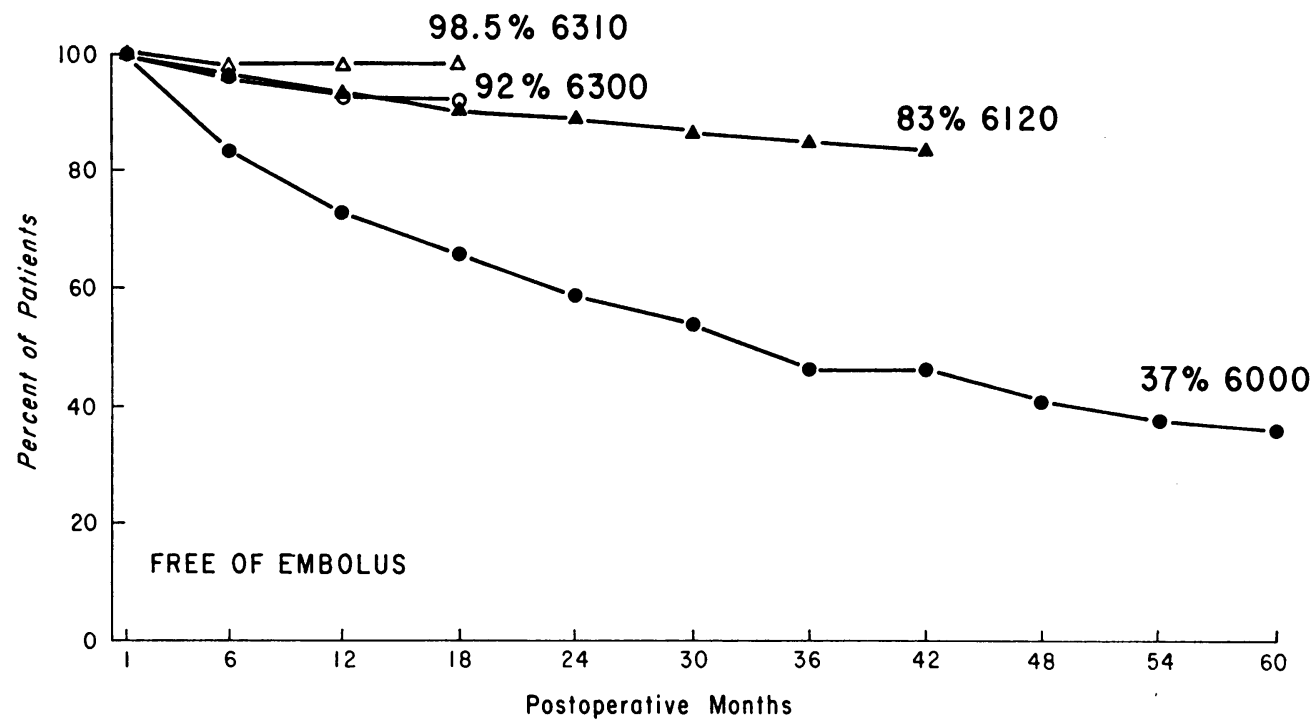

FIG. I5 Late thromboembolic complications related to valve design in patients with isolated mitral replacement.

aphasia with complete recovery, and without an adequate follow-up system would have gone unrecognized. Thus 72 per cent of the patients were free of late embolism and an additional 17 per cent had no significant disability due to embolus.

Thromboembolic episodes occurring during the first postoperative month were noted in 8 per cent of the isolated mitral valve patients and 6 per cent of the multiple valve cases. Most occurred with the older style valve. Thus the incidence of early embolic complications was 4 per cent for the Model 6000 valve,

FIG. I6 Severity of embolic complications after mitral valve replacement.

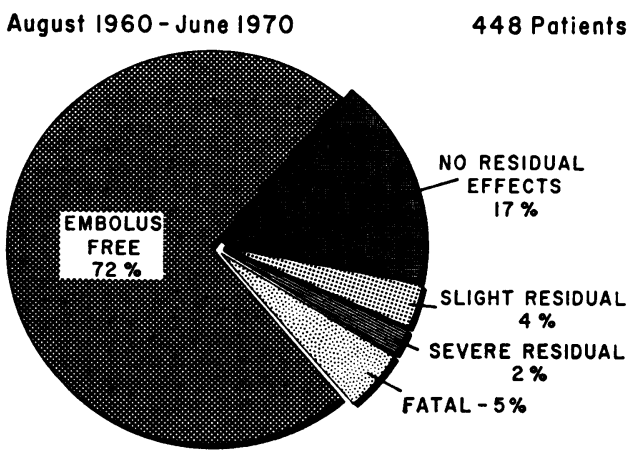

0.3 per cent for the 6120,2 per cent for the 6300 , and I per cent for the 6310. The apparent lack of improvement with the completely cloth-covered valves compared with the extended cloth valve (Model 6120) is not surprising, since thrombus formation would not necessarily be suppressed until healing occurred.

While the slopes of the actuarial curves provide useful information with regard to the risk of embolism related to time, the number of patient months of follow-up with each type of valve is not shown. Table 4 presents this information in terms of the incidence of thromboembolic complications per $\mathrm{r}, 000$ patient months of follow-up. The improvement provided by the 6120 prosthesis is striking. The excellent results obtained with the 6310 prosthesis are related to an experience only one-

TABLE 4 Incidence of late thromboembolic complications related to valve design in 312 patients, August 1960 to fune 1970

\begin{tabular}{lll}
\hline $\begin{array}{l}\text { Isolated mitral } \\
\text { Model No. }\end{array}$ & $\begin{array}{l}\text { Follow-up in } \\
\text { patient months }\end{array}$ & $\begin{array}{l}\text { Incidence/Iooo } \\
\text { patient months }\end{array}$ \\
\hline 6000 & 5855 & $14 \cdot 3$ \\
6120 & 2837 & $5 \cdot 2$ \\
6300 & 969 & $3 \cdot 1$ \\
6310 & 629 & $1 \cdot 4$ \\
\hline
\end{tabular}


tenth as large in patients with follow-up as with the Model 6000 prosthesis and must be interpreted with caution at this time. The 6310 sample in this table contains a larger percentage of early months of follow-up than the sample related to the Model 5000 or 6120. Since during the early months the incidence of thromboembolic complications is greater, the Model 6310 sample contains a bias in the direction of increasing the incidence of this complication. Despite this the incidence of I.4 per I,000 patient months with the Model 6310 valve is significantly less than the 14.3 figure for the 6000 series and 5.2 for the 6120 series.

The earliest cloth-covered prosthesis (Model 6300), supplanted now by the composite seat valve (Model 6310), has given disappointing results in terms of the incidence of thromboembolic complications compared with the current non-cloth-covered valve (Model 6120). This may be due to the less optimal flow characteristics of the Model 6300. The actuarial curves for both clothcovered prostheses, however, show a diminishing slope with time, a feature not noted with the non-cloth-covered valves.

\section{Functional results}

The functional results of mitral replacement with the ball valve prosthesis have been described in multiple publications from this clinic during the past decade (Bristow et al., 1965, 1966; Starr, Herr, and Wood, 1967). Late cardiac catheterization demonstrates satisfactory hydraulic function of all the various model mitral prostheses with the exception of the smaller sized earlier clothcovered valve (Model 6300). The mean diastolic rate in a group of such patients was $9.4 \mathrm{~mm}$. $\mathrm{Hg}$ with the Model 6300 valve compared with $4.9 \mathrm{~mm}$. $\mathrm{Hg}$ with the composite seat valve of Model 6310 (Kloster et al., 1969; Hodam et al., 1970). Restriction of cardiac performance due to the presence of a rigid ring in the mitral annulus has not been documented in the experimental animal (Tsakiris et al., 1967; Rastelli and Kirklin, 1966; Rastelli et al., 1966, 1967). The restriction of function after mitral valve replacement in the absence of leak or thrombotic stenosis is almost always due to myofibrosis, coronary artery disease, residual disease of other valves, or chronic pulmonary disease (Peterson et al., 1967). Subjectively 71 per cent of the patients are greatly improved after operation, with normal exercise tolerance. Salt or fluid restriction is not usually necessary and digitalis is used only for chronic atrial fibrillation. While 80 per cent of the patients in chronic atrial fibrillation before mitral valve replacement maintain this arrhythmia after surgery, 20 per cent of such patients are eventually converted to sinus rhythm within one or two years of operation. The remaining patients have a less than optimal result after operation. Approximately 17 per cent remain limited in activity tolerance with persistent cardiomegaly, and require digitalis and salt restriction, but are slightly improved from their preoperative status. Five per cent of the patients are essentially unchanged by operation, and such patients usually have had many years of severe disability with massive cardiomegaly and chronic congestive heart failure. Three per cent are worse, and in four per cent of the patients the results are undetermined.

\section{Discussion}

The selection of the method of choice for replacement of the mitral valve depends on features already reviewed, such as ease of implantation with a low operative mortality, satisfactory hydraulic function, and the incidence of late complications. In addition, consideration must be given to the need for complicated or dangerous long-term drug therapy and the durability of the prosthesis, whether of synthetic or biological origin. Long-term anticoagulant therapy has been employed in the overwhelming majority of patients having ball valve replacement in this clinic. However, with the development of the cloth-covered valves a double-blind study has been under way with half of the patients receiving a placebo rather than coumadin. The results of this study are not yet significant. In addition to the study patients, ro other patients have not received anticoagulant treatment for a variety of reasons either medical or socioeconomic. Despite this the incidence of thromboembolic complications with the Model 6310 mitral prosthesis is extremely low. The incidence of thromboembolic complications with the composite seat aortic prosthesis (Model 23IO) is zero up to July 1970. Whether it will be possible to discontinue the routine use of anticoagulant therapy after valve replacement with the current generation of cloth-covered valves remains to be seen. This is a distinct possibility, however, and it is our present practice to avoid anticoagulant treatment in patients undergoing valve replacement in whom, for one reason or another, the use of anticoagulants poses a special hazard.

The effect of mitral valve disease and mitral valve replacement on red blood cell survival has been previously reported (Brodeur et al., 1966). Chronic traumatic haemolytic anaemia 
is unknown after mitral valve replacement with the various model ball valve prostheses except in the presence of perivalvular leak. In these circumstances the anaemia responds immediately to surgical correction.

There has not been a significant durability problem with the mitral ball valve prosthesis though clinical experience now approaches ten years. In one patient in our series with double replacement, fatty infiltration of the silicone rubber ball of the mitral prosthesis occurred in conjunction with severe ball variance of the aortic prosthesis (Starr et al., 1966b; Hylen et al., 1968, 1969a, b, 1970; Herr et al., 1968). In this patient the mitral prosthesis was tilted into the aortic outflow tract so that the ball was exposed to the same magnitude of high velocity flow as the ball in the aortic position. Four additional cases of fatty infiltration of the silicone rubber ball in the old Model 6000 valves have been reported to the manufacturer. This is in conspicuous contrast to the problem of aortic ball variance, of which there are more than 197 cases known to the manufacturer, Ball variance has not been seen with the Model 6120 mitral valve introduced in March 1965. With the development of the cloth-covered valves this problem has been circumvented by the use of a hollow metallic ball.

\section{References}

Bristow, J. D., Farrehi, C., McCord, C. W., Starr, A., and Griswold, H. E. (1965). Clinical and hemodynamic observations after combined aortic and mitral replacement. Circulation, 31-32, Suppl. 1, 67.

, Kloster, F. E., Herr, R. H., Starr, A., McCord, C., and Griswold, H. E. (1966). Cardiac catheterization studies after combined tricuspid, mitral, and aortic valve replacement. Circulation, 34, 437.

Brodeur, M. T. H., Koler, R. D., Starr, A., and Griswold, H. E. (1966). Red blood survival in patients with mitral valvular disease and mitral valve prostheses. Circulation, 33-34, Suppl. I, 140.

Herr, R. H., Starr, A., Pierie, W. R., Wood, J. A., and Bigelow, J. C. (1968). Aortic valve replacement: a review of six years' experience with the ball-valve prosthesis. Annals of Thoracic Surgery, 6, 199.

- Hodam, R., Starr, A., Raible, D., and Griswold, H. (1970). Totally cloth-covered prostheses: a review of two years' clinical experience. Circulation, 41-42, Suppl. 2, 33.

Hylen, J. C., Judkins, M. P., Herr, R. H., and Starr, A. (1969a). Radiographic diagnosis of aortic-ball variance. fournal of the American Medical Association, 207, 1120.

—, Kloster, F. E., Herr, R. H., Hull, P. Q., Ames, A. W., Starr, A., and Griswold, H. E. (I968). Phonocardiographic diagnosis of aortic ball variance. Circulation, 38, 90.

,,--- Starr, A., and Griswold, H. E. (I969b). Sound spectrographic diagnosis of aortic ball variance. Circulation, 39, 849.

,-- , Starr, A., and Griswold, H. E. (1970) Aortic ball variance: diagnosis and treatment. Annals of Internal Medicine, 72, 1 .

Kloster, F. E., Herr, R. H., Starr, A., and Griswold, H. E. (1969). Hemodynamic evaluation of a cloth-covered Starr-Edwards valve prosthesis. Circulation, 39-40, Suppl. I, 119.

Peterson, C. R., Herr, R., Crisera, R. V., Starr, A., Bristow, J. D., and Griswold, H. E. (1967). The failure of hemodynamic improvement after valve replacement surgery. Annals of Internal Medicine, 66, 1 .

Rastelli, G. C., and Kirklin, J. W. (1966). Hemodynamic state early after prosthetic replacement of mitral valve. Circulation, 34, 448 .

_- Tsakiris, A. G., Banchero, N., Wood, E. H., and Kirklin, J. W. (I966). Cardiac performance after replacement of the dog mitral valve with StarrEdwards prosthesis with and without preservation of the chordae tendineae. Surgical Forum, 17, 178.

, - Frye, R. L., and Kirklin, J. W. (1967). Exercise tolerance and hemodynamic studies after replacement of canine mitral valve with and without preservation of chordae tendineae. Circulation, 3536, Suppl. I, 34

Starr, A. (1969). Acquired disease of the tricuspid valve. In Surgery of the Chest. Ed. by J. H. Gibbon, Jr., D. C. Sabiston, Jr., and F. C. Spencer, p. 770. Saunders, Philadelphia.

- , and Edwards, M. L. (196I). Mitral replacement: clinical experience with a ball-valve prosthesis. Annals of Surgery, 154, 726.

- - McCord, C., Wood, J., Herr, R., and Griswold, H. E. (I964a). Multiple-valve replacement. Circulation, 29, Suppl. I, 30.

—, Herr, R. H., and Wood, J. A. (1966a). Tricuspid replacement for acquired valvular disease. Surgery, Gynecology, and Obstetrics, 122, 1295.

- - - and - (1967). Mitral replacement: review of six years' experience. Fournal of Thoracic and Cardiovascular Surgery, 54, 333.

-, McCord, C. W., Wood, J., Herr, R., and Edwards, M. L. (1964b). Surgery for multiple valve disease. Annals of Surgery, 160, 596.

—, Pierie, W. R., Raible, D. A., Edwards, M. L., Siposs, G. G., and Hancock, W. D. (1966b). Cardiac valve replacement: experience with the durability of silicone rubber. Circulation, 33-34, Suppl. I, II 5.

Tsakiris, A. G., Rastelli, G. C., Banchero, N., Wood, E. H., and Kirklin, J. W. (1967). Fixation of the annulus of the mitral valve with a rigid ring. Hemodynamic studies. American fournal of Cardiology, 20, 812. 